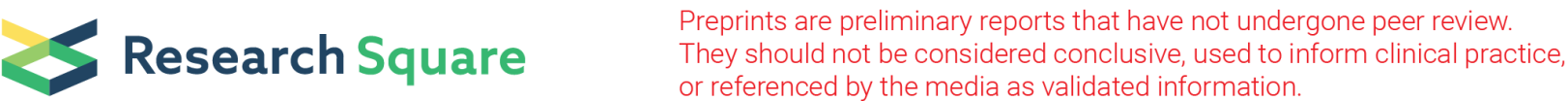

\section{A Mechanistic insight into chemical cues and interactions involved in herbivory induced jasmonate mediated plant defense mechanism}

Qudsia Yousafi

COMSATS University Islamabad Sahiwal Campus

Amina Hafeez

COMSATS University Islamabad Sahiwal Campus

Muhammad Saad Khan

COMSATS University Islamabad Sahiwal Campus

Shabana Bibi ( $\square$ dazzling.grin@gmail.com )

Yunnan University

Muhammad Ajmal Shah

Government College University

Maryam Liaqat

Okara University

Shahzad Saleem

COMSATS University Islamabad Sahiwal Campus

Muhammad Wasim Sajid

COMSATS University Islamabad Sahiwal Campus

Asim Mehmood

COMSATS University Islamabad Sahiwal Campus

Mohammed Alqarni

Taif University

Renald Blundell

American University of Malta, Triq Dom Mintoff

\section{Research Article}

Keywords: Insect elicitors, Allene oxide peroxidase, Hydroxyperoxide lyase, Jasmonic acid, Green leafy volatiles

Posted Date: March 29th, 2021

DOI: https://doi.org/10.21203/rs.3.rs-301673/v1 
License: (c) (i) This work is licensed under a Creative Commons Attribution 4.0 International License. Read Full License 


\section{Abstract}

The first step in plant defense mechanism is to sense the insect attack stimulus. Plant sensitivity of an insect attack is the first step of defense. Molecules generated by the oral secretion of the insect interact with the plant receptors to trigger plant defense mechanisms. We selected some highly cited insect elicitors molecules, volicitin, caeliferin, bruchin which interact with plant defense by interacting with plant elicitors (systemin, inceptin and peps) located on the plant cell surface. This interaction activates plant receptors SYR1, LRR, PEPR and triggers downstream defense signaling. The octadecanoid pathways, involving enzymes allene oxide synthase (AOS) and Hydroxyperoxide lyase (HPL) are activated. These enzymes mediate production of green leafy volatiles and Jasmonic acid by interacting with hydroxperoxide molecules. We docked the elicitors with receptors and enzymes with substrates in the pathway of JA production. Phe was found to be an important amino acid that interacts with 13hydroxyperoxides in the case of AOS to produce JA but not in the case of HPL. JA is converted to JA-lle which shows strong binding with COI1 and COI1-JA-lle complex docked with JAZ which showed strong interaction with five hydrogens and one salt bridge bond. AOS and HPL showed less than $40 \%$ identity for sequence and structure alignment. AOS and HPL had shown an interaction between each other and showed a common interaction partner of the Lipoxygenase family. HPL shows interaction with ADH2 (Alcohol dehydrogenase) involved in GLVs production. AOS also showed interaction partner AOC, COI1 and OPR1 which are involved in JA-induced plant defense mechanism.

\section{Introduction}

The insect plant ratio on our planet is interestingly high. Three hundred thousand plants have one million insect pests to compete with. Both the competitors, plants and insect, have evolved intricate and sophisticated strategies to survive within this aura of competition ${ }^{1}$. Some counter defense strategies developed by plants include production of secondary metabolites, repellents, antifeedants and morphological features modification ${ }^{2}$. Right after any damage cue sensed the plants promptly synthesize and discharge organic/inorganic volatile compounds as first step in preparation for defense strategies against attack ${ }^{3}$. These oral secretions in the form of regurgitates or saliva play key role in plant defense mechanism against herbivory ${ }^{4}$. The insect pest have diversified mode of feeding due to their different types of mouthparts this make them more adaptable than other fauna on earth.

Insect contributes to the largest group of the herbivores on the planet ${ }^{5}$ and this tends to the development of diverse counter defense strategies, against insect attack, by plants ${ }^{6}$. Although the execution and maintenance of this sophisticated mechanism is expensive for plants but this cost is inevitable for their survival in insect pest dominating environment ${ }^{7,8}$. This defense mechanism is invoked by direct insect pest attack/physical contact or by sensing the chemical cues from neighboring plants attacked by insect $9 \cdot 10$. Insect generated signals by physical contact ${ }^{11}$ ovipositional fluid ${ }^{12}$, feces ${ }^{13}$, pheromone ${ }^{14}$ and insect feeding vibrations ${ }^{15}$ can be sensed by the plants result in initiation of plant defense cascade activation. The production, behavior and effect of insect oral secretion have been studied extensively in 
context of plant defense mechanism against herbivory ${ }^{16}$. Oral secretions of the insects are divided in two broad categories as per their origin i.e., salivary fluid secreted from salivary gland and those derived from the gut called regurgitate. Both types of the secretions are rich in chemical compounds which can become elicitor or repressor of plant defense mechanism ${ }^{17}$.

Plants have developed very sensitive mechanisms to foresee and sense the danger of herbivory. A very intricate and synchronized coevolution has been developed between insects and plants. The key players for the initiation of plant defense are diversified chemical like insect-derived elicitors damage-associated molecules, plant hormone systems activated by insect oral secretion compounds ${ }^{4}$. Volicitin, $\mathrm{N}-(17-$ hydroxylinolenoyl)-L-glutamine (volicitin), was first insect oral secretion detected elicitor molecule in beet armyworm larvae, Spodoptera exigua ${ }^{18}$. Volicitin was also reported to be involved in synthesis of the volatile insect predator attractants after herbivores attacking maize plants ${ }^{19}$. Other insect small peptide elicitors like Inceptins have also been reported which are present both in plant and insect regurgitate. Inceptins, firstly reported in Spodoptera frugiperda oral secretions, are proteolytic fragments of a chloroplastic ATP synthase c-subunit that are generated in the insect midgut and induce defenses in cowpea and beans ${ }^{20}$. These disulfide-bonded peptides are synthesized by protein degradation fragments of the chloroplastic ATP synthase ( $\gamma$-subunit), formed in Spodoptera frugiperda gut by the digestion of plant proteins ${ }^{20}$. The most common inceptin receptors in plant are leucine-rich repeat receptor-like protein (INR) ${ }^{21}$. Caeliferins a disulfoxy fatty acids were identified in the oral secretions of Shistocerca americana (American bird grasshopper) oral secretions were reported to contain a disulfoxy fatty acid compound called caeliferin ${ }^{19}$. Bruchins is another important elicitor was isolated from the oral secretions of Callosobruchus maculatus and Bruchus pisorum ${ }^{18}$.

Several defense signals are activated in plant right after insect herbivory which results initiation of different plant defense responses ${ }^{22}$. The first injury-induced peptide signal (elicitor) produced in plant was an eighteen amino acid long peptide named systemin. It was reported to be derived from its inactive form prosystemin right after insect bite in tomato ${ }^{23}$. Systemin promotes Jasmonic acid buildup in plant cells and triggers the genes expression for the production of defense related plant proteins ${ }^{24}$. A leucinerich repeat receptor kinase (LRR-RK), called SYR1 has been reported as a receptor of systemin in plants 25. Later some other injury-induced peptide based plant elicitors had been identified. The application of synthetic twenty three amino acid long maize Peps could mimic the Spodoptera exigua attack and found to induce jasmonic acid production ${ }^{26}$. A short peptide AtPeps acts as signals to activate both jasmonic and salicylic acid signaling pathways in Arabidopsis ${ }^{27}$. The reported receptors of AtPeps-AtPEPR1 and AtPEPR2-are classified under the LRR-RK protein family ${ }^{28,29}$.

The allene oxide synthase (AOS) and hydroxyl peroxide lipase (HPL) enzymes, responsible for the production of defense signals in the form of jasmonates and aldehydes (GLVs), respectively ${ }^{30}$, uced response of the plants in response to injury or damage is one of the significant components of insect pest control strategies in agriculture for the management of pest population ${ }^{31-33}$. By increasing the host 
plant resistance we can minimize the use of insecticides which in turn. Genetically modified crops have been introduced during last two decades were found to be more economical to cultivate than the use of insecticides extensively.

This study can be proved more helpful in investigations and revelation of plant stress response pathways, interactions structure, and function of proteins involved. In this project we attempt to cover the entire chain of herbivory defense cascade from the recognition of a feeding insect pest, through the production of defense molecules or utilization of physical defenses. Firstly, the primary events of herbivory induced the defense responses are studied and later complex intracellular signaling cascades was predicted, with a special focus on the jasmonate pathway.

\section{Results}

The objective of this study is to determine the interactions among the insect/plant elicitors and receptor molecules in herbivory induced plant defense mechanism pathway (Fig. 1).

\section{Three-dimensional protein structure prediction}

The first step in a proteomic study is to have the 3D structure of the protein. 3D structures of the selected protein could not be found Protein Data Bank (PDB) so predicted through I-TASSER and MODELLER. The online server I-TASSER send the results via email containing five models, against each submitted query sequence, with different confidence levels (C-score). The models with high scores were selected and evaluated for quality check. The predicted 3D protein models, either from MODELLER or I-TASSER were refined and evaluated and good quality models were selected (Table 2) (Fig. 2-3)

\section{Docking Analysis Interaction of insect elicitor molecules with plant elicitors}

Docking was performed on all selected inhibitors by using AutoDock Vina. The main purpose of docking was to find the potential interactions between insect elicitor molecules and plant receptors to find out how these molecules interact with each other to trigger plant defense pathways (Table 3). The lowest binding energy $(-6.9 \mathrm{kacl} / \mathrm{mol})$ was recorded for the Volicitin-Systemin complex (Fig. 4a) followed by that of the Volicitin-PEP1 complex (-6.8kcal/mol) (Fig. 4b). The highest number of hydrogen bonds (5) was found in Caeliferin-Systemin (Fig. 4c) and Bruchin-PEP1 complexes (Fig. 4d). The hydrogen bond distance among the docked complexes was ranging from 2.7 to $3.17 \AA$ which reflects good interaction strength (Fig. 4a-f).

\section{Interactions of plant elicitors with plant receptors}

Protein-Protein docking was done by the PatchDock server. The input of this server is two molecules of any type: proteins, DNA, peptides, drugs. The output is a list of potential complexes sorted by shape complementarity criteria. The amino acid interaction between docked proteins was observed through DIMPLOT (Table 4). Overall a strong interaction was observed as the hydrogen bond distance for all the 
interactions were less than $3 \AA$ (Fig. 5a-C). Systemin-SYR1 formed the highest numbers (8) of hydrogen bonds (Fig. 5a). Inceptin, although released from insect regurgitate, acts as a plant elicitor and interacts with plant receptor LRR by forming a strong hydrogen bond of $2.59 \AA$ bond distance (Fig. $5 \mathrm{C}$ ).

\section{Jasmonate biosynthesis}

\section{Interaction of AOS and HPL with their ligand molecules}

Hydrogen bonding in the protein-ligand complex was found for both proteins (Table 5). The lowest binding energy $(-6.7 \mathrm{kcal} / \mathrm{mol})$ has resulted in the 13(S) Hydroperoxide-HPL complex (Fig. 6a). Four hydrogen bonds, with bond distances ranging between 3.20 and $2.55 \AA$, were found in $13(\mathrm{~S})$ Hydroperoxide-AOS complex (Fig. 6b). The hydrogen bond interactions of 9(S) Hydroperoxide with HPL and AOS are shown in Figs. 6c-d.

\section{Jasmonate signaling and regulation Interaction of COI1 with JA-lle}

Coronatine Insensitive Protein 1 (COI1) is a nucleus receptor that binds with the JA-lle (Jasmonate Isoleucine) to degrade JAZ (Jasmonate ZIM domain) protein. The complex was docked successfully with $-5.8 \mathrm{kcal}$ of binding energy. Three good strength hydrogen bonds $(2.81-3.01 \AA$ ) were also observed (Fig. 7a-b).

\section{Interaction of COI1 receptor with JAZ protein}

JAZ proteins inhibit the activity of MYC2 by bindinding to their respective transcription factors. The production and deposition of Jasmonic acid in damaged cells is the first response herbivory or mechanical damage to the plants. The jasmonic acid further converted to (+)-7-iso-JA-L-lle. This binds to coronatin-insensitive 1 (COI1) protein. This event leads to the binding of COI1 with Jasmonate ZIMdomain (JAZ) protein. This complex is recognized by $26 \mathrm{~S}$ proteasome and JAZ is degraded by ubiquitination process ${ }^{4}$.

Keeping in view evidence from literature, that JA-lle- COI1 binds to JAZ which leads to its ubiquitination of JAZ by 26 S proteasome ${ }^{4}$, we performed protein-protein docking of JA-lle- COI1 complex with JAZ by assigning JA-lle- COI1 as ligand and JAZ as a receptor. The resulting docked complex showed a lower binding affinity of $-8.20 \mathrm{kcal} / \mathrm{mol}$. Seven hydrogen bonds were formed with bond distance ranging from 2.61 to $3.21 \AA$ and one salt bridge bond between Arg211 (JAZ) and Glu203 (COI1) (Fig. 8a-b).

\section{Protein-protein interaction)}

STRING database was used to find out the interaction partner of Hydroperoxide lyase and Allene oxide synthase.

\section{Allene Oxide Synthase (AOS)}

Eleven nodes and thirty-six edges with an average clustering coefficient of 0.829 were observed in the case of AOS (Fig. 9). The interaction with ten proteins in the network was based on co-expression and 
text mining. AOC showed the highest homology score (0.979) through co-expression followed by that of HPL (0.907) through text mining and co-expression and loxD (0.863) through co-expression.

\section{Hydroperoxide lyase (HPL)}

Eleven nodes and twenty-nine edges with an average clustering coefficient of 0.471 were observed in the case of HPL (Fig. 10). The interaction with ten proteins in the network was based on co-expression and text mining. ADH2 showed the highest homology score (0.971) through text mining followed by that of loxC (0.693) through text mining and co-expression and Solyc09g055900.2.1 (0.958) through coexpression and text mining.

\section{Protein sequence and structure alignment}

The sequences show only a percent similarity of 60.7 while percent identity 35.9 was observed (Fig. 11). In the case of 3D structure superposition, the percent identity was 37.3 was observed (Fig. 12a-b).

\section{Discussion}

The plants and insects have an intricate evolution history. Both coevolved sometimes as mutualistic relations and mostly as competitors. Insect plant co evolution is the most speedily occurring event in nature. As the insects acquire advanced capabilities to damage plants in turn the plants response back to the damage by modifying it defense machinery. This is the interplay of insect-plant chemicals to become winner. The first and foremost event in initiation of plant defense mechanics is the recognition of the stimulus by plant receptor cells. Insect oral secretions induces several internal signals from the wounded tissues, including jasmonate signaling ${ }^{39,40}$. Although many oral secretions might not serve a specific function to the insect, salivary proteins play a more active role in modulating the interactions between plant and insect herbivore ${ }^{41-43}$. The plants release volatile compounds such as repellents for insect pest and attractants for pasitoides/predators act as an alarm for herbivore attack ${ }^{44}$. The signals in the form insect oral secretion elicitor compounds are perceived by plant elicitors and induce defense responses afterwards. Jasmonic acid is the key player of insect herbivory induced plant defense mechanisms in plants.

In the current study, we selected literature that reported insect-derived elicitors and predicted their interaction with plant elicitors and receptors in the Jasmonic acid pathway. The 2D structures were downloaded from PubChem in .sdf format and later converted into .pdb format through Chimera. The sequence of plant-derived elicitors was retrieved through UniProt in FASTA format. The 3D structure of plant receptors was not available in Protein Data Bank (PDB) those were modeled through homologybased modeling (Modeller) and Ab-initio method (I-TASSER). I-TASSER server uses multiple templates to predict protein structure ${ }^{45}$. It generates five models with different confidence scores. Good quality models with high $\mathrm{C}$ scores ${ }^{46,47}$ were selected for further analysis.

During insect herbivory there are lots of elicitor molecules that are released from the oral secretions of insects, however, for this study we have selected highly cited elicitor molecules i.e., volicitin, caeliferin, 
bruchin and inceptin. Volicitin (N-(17-hydroxylinolenoyl)-I-GIn) a small fatty acid derived molecule was first reported in the corn seedling wounds caused by beet armyworm feeding ${ }^{19}$ In the current study, findings show a strong interaction between plant elicitor peptides and their receptors with hydrogen bond distance less than $3 \AA$ which reflects a strong bonding ${ }^{48}$ between insect oral secretion chemical compounds and plant elicitors, Systemin and PEP1. This confirmed the findings that insect oral secretions contain the compounds which can induce defense responses of plants and cause higher levels of JA production as compared only to mechanical damage ${ }^{40,49}$. Our results confirmed previous findings as reported by Chen $\&$ Mao ${ }^{4}$ who reported that elicitors derived from insects can activate plant defense by interacting with plant elicitors Systemin and PEP1. The receptors of these elicitors present on the epithelial cells are SYR1, LRR PEPR1 upon receiving signals they initiate a cascade of plant defense signaling network. After this several changes occur in a plant cell all these changes consider as early plant defense responses by the production of Jasmonic acid ${ }^{50}$. These changes activate jasmonate acid (JA) production in the plant. Afterward, certain changes occur in the peroxisome of a plant cell. All these changes in plant cells activate the OPDA pathway. Jasmonic acid and its primary precursor fatty acid derived12-oxophytodienoic acid (OPDA) enzymes are the most studied oxylipins ${ }^{51}$. These OPDA enzymes, include Hydroxyperoxide lyase and Allene oxide synthase, play the role of key mediator in the production pathway of green leafy volatiles and jasmonic acid respectively. Molecular docking of AOS and HPL, with their ligands $9(\mathrm{~S})$ and $13(\mathrm{~S})$ hydroxyperoxides ${ }^{52}$, was done through AutoDock Vina and analyzed the results by using LIGPLOT. Both AOS and HPL showed good interaction with the ligands. Allene oxide synthase belongs to the cytochrome P450 family of enzymes, interacts with 9- or 13hydroxyperoxides and act as catalytic agent in jasmonate production in plant cell chloroplast ${ }^{37}$ hence proved. Hydroxyperoxide lyase another important enzyme catalyzes the production of GLVs by using the same substrates ${ }^{53}$. Our finding confirmed that not only AOS but HPL interact with 9(S) and 13(S) hydroxyperoxides to mediate the Jasmonic acid synthesis pathway. JA and JA-lle induced by systemin act as signals and are transported to adjacent sites for defensive responses ${ }^{54}$. The Jasmonic acid shifts towards cytoplasm then converted to JA-lle (Jasmonate Isoleucine) and interact with nuclear receptor COI1 (Coronatine Insensitive Protein 1). This interaction causes the degradation of JAZ protein that holds transcription factor MYC2. this induces downstream gene expression for defense protein formation ${ }^{55}$. Our results show a strong interaction between JA-lle and COI1 with three hydrogen bonds at a bond distance of less than $4 \AA$. The MYC transcription factors by bind to JAZ protein and activates JA-lle-COI1 complex and degrade of JAZ with the help of $26 \mathrm{~S}$ proteasome ${ }^{39}$. Three dimensional structure COI1 and JAZ complex is evident of its high binding affinity with JA-lle compound ${ }^{56}$. We docked the COI1-JA-lle complex with JAZ and predicted strong interaction showing five hydrogen bonds each with less than $4 \AA$ distance. Seven hydrogen bonds were formed and a salt bridge bond was also found. The salt bridge most often arises from the anionic carboxylate (RCOO-) of either aspartic acid or glutamic acid and the cationic ammonium (RNH3+) from lysine or the guanidinium ( $\mathrm{RNHC}(\mathrm{NH} 2) 2+)$ of arginine ${ }^{57}$. The bond distance required for good interaction must be $\leq 4 \AA(400 \mathrm{pm})^{58}$. 
At the end Jasmonic acid activate defense responsive genes and the plant shows the JA mediated response. the F-box COI1 protein, which functions as part of the JA receptor, interacts with the Skp1/Cullin counterparts to form the Skp1-Cullin-F-box (SCF) COI1 ubiquitin E3 ligase complex and interacts physically with JAZ repressor proteins in the presence of JA conjugated with the amino acid isoleucine and convert to jasmonoyl-L-isoleucine (JA-lle). This is an active form of $\mathrm{JA}^{59}$ which switch on the defense related plant genes ${ }^{60,61}$.

The study of Arabidopsis AOS protein-protein interaction mechanism and structure elucidation has been reported before by Lee et al. ${ }^{62,63}$.The Protein-Protein interaction of AOS and HPL was done by using the STRING database to further confirm the interaction partners of these proteins in the JAS production pathway. The biosynthesis of JA starts with -linolenic acid which is converted to its 13(S) hydroperoxylinolenic acid by 13-LOX; the LOX product is subsequently converted to jasmonic acid by sequential action of allene oxide synthase (AOS), allene oxide cyclase (AOC) and 12-oxo-phytodienoic acid reductase (OPR) while HPL and ADH2 lead to the biosynthesis of GLV ${ }^{64-67}$. The results confirm the above findings. Both AOS and HPL had shown an interaction between each other and showed common interaction partners of the Lipoxygenase family i.e., loxC, Solyc09g0559002.1, 101263024 and loxc. AOS also showed interaction partner AOC, COI1 and OPR1. Lipoxygenases (lox) are a ubiquitous family of non-heme iron enzymes widely distributed in plants, initiate hydroperoxidation of polyunsaturated fatty acids and produce phytooxylipins (jasmonic acid and GLVs) responsible for physiological processes like seed germination, fruit ripening, senescence and defense (against biotic and abiotic stress) ${ }^{68}$.

HPL shows interaction with ADH2 (Alcohol dehydrogenase). Alcohol dehydrogenases (ADHs) belong to the dehydrogenase superfamily ${ }^{69}$. GLVs originate in the hydroperoxide lyase (HPL) branch of the oxylipin pathway, with the help of $A D H 2{ }^{70-72}$. Which is a crucial plant defense signal of in result of herbivory ${ }^{73}, 74$

The pairwise alignment of AOS and HPL showed $39.5 \%$ identity and $60.7 \%$ similarity. Structural superposition showed a similar trend with $37.5 \%$ identity these results confirm that although AOS (CYP74A) and HPL (CYP74B) are closely related members of the CYP74 family and interact with the same set of substrates (13-h) yet result in diverse products. Our findings confirmed the information given by Tyagi et al. ${ }^{75}$. They found the $\mathrm{F}$ amino acid plays important role in binding with 13 - hydroxy peroxide for the production of jasmonic acid. They also observed that the F in AOS sequence (involved in binding with substrate) is replaced by $L$ in HPL of Japanese rice. In our study we found to $F$ amino acids in AOS were found to interact with 13-hydroxy peroxide but no $\mathrm{F}$ was involved in HPL-13 hydroxy peroxide interaction. The HPL also showed interaction with ADH2 which leads to producing GLVs but commonly interacting with lox.

Our findings suggest that these two branches (AOS and $\mathrm{HPL}$ ) of the oxylipin pathway exhibit crosstalk with regards to biosynthesis and signaling and cooperate to function in multiple abiotic stress responses $^{76}$ 


\section{Materials And Methods}

\section{Selection and retrieval of Insect/plant elicitors and receptors}

Insects release various chemical compounds, from their oral secretions (regurgitate and saliva) during herbivory which activate defense mechanisms in plants. We have selected highly cited elicitor molecules involved in plant defense pathway activation. The structures of selected molecules were downloaded in sdf (structure-data file) format through PubChem and converted to .pdb format through PyMol (Table 1). Inceptin is a proteolytic fragment produced by insect larvae that previously ingested the plant protein and mediates plant perception of herbivory. This is categorized both as insect/plant elicitor. The amino acid sequences of some plant elicitors (and inceptin) and receptors were retrieved from UniProt (Table 2).

\section{Protein 3D Structure Prediction}

Three-dimensional (3D) structures of the proteins not available in PDB were predicted through homology and $A b$-initio methods. Protein BLAST of the protein sequences was done through NCBI BLASTp (selecting PDB dataset) to get good templates for use in homology modeling. The 3D structures of proteins, having more than $35 \%$ identical templates, were modeled by homology modeling. Homology modeling was done by using an offline tool Modeller 9.1. The protein which could not result in an identical template $(<35 \%)$ were predicted through $A b$-initio based structure modeling method. The protein FASTA sequences were submitted to an online available server

I-TASSER for Ab-initio based structure modeling. ModRefiner a web-based server was used to by using $A b$-Initio modeling ${ }^{34}$. The quality of the predicted models have to be evaluated by different evaluation tools to ensure its quality. The refinement of low quality structures was done Galxyweb server. The refined models were submitted to the SAVES server, which uses different sets of structure evaluation platforms and qualified models were selected.

\section{Docking Analysis}

Docking analysis of protein-ligand interaction was done by using Auto Dock Vina while protein-protein docking was done by using the online available server Patch Dock. The strongest binders were identified based on lower binding energy and hydrogen bonding.

\section{Protein-ligand with Auto Dock Vina}

Auto Dock Vina is an offline sever it has GUI-based MGL tools, ligand and protein preparations and a Command line-based interface for the execution of molecular docking. First of all, the pdb files of ligand and protein files were subject to charges addition and converted to. pdbqt format. Grid was set for blind docking then a configuration file was prepared to run in the command line for docking. Five models were generated and the model with the lowest binding energy and RMSD value was selected. All the models were deleted from the output.pdbqt file except the selected one. This output.pdbqt file was used for interactive visualization. 
Protein-Protein docking was done by an online available serve Patch Dock. It works on a molecular docking algorithm based on shape complementarity principles ${ }^{35}$. Three dimensional models of proteins (.pdb) to be docked were uploaded to server. The results were received via email in the form of the compressed folder of the top 20 selected complexes. The docked complexes were subjected for refinement through the online available server Fast Interaction REfinement in molecular DOCKing (FireDock). The protein-ligand and receptor pdb files and a Patch Dock generated, Tarsansformations.txt file was uploaded to the server for refinement. The resulting best-scored docked complex was selected based on lower binding energy.

\section{Docking result visualization}

Complex. pdb files were uploaded to LIGPLOT + to visualize interactions in the docked complex. Proteinligand was visualized by selecting the option LIGPLOT while Protein-Protein interaction was visualized by selecting option DIMPLOT. The 2-D structure of the complex was generated showing hydrogen bonding and hydrophobic interactions. BIOVA DISCOVERY STUDIO ${ }^{36}$ was used for 3D visualization of a docked protein complex.

\section{Jasmonate biosynthesis pathway}

The interactions of insect elicitors with plant receptors activates different plant defense through different pathways. We selected the Octadecanoid pathway, which produces jasmonic acid (JA), for our study. JA is the main regulator of the plant defense mechanism.

AOS (Allene oxide synthase) and HPL (Hydroxyperoxide lyase) are the two main enzymes of jasmonic acid (JA) and Green leafy volatiles (GLV) production pathway. AOS and HPL were selected to study how they are involved in Jasmonic acid production. The amino acid sequences of both enzymes were obtained from UniProt under Q9LLB0 (AOS) and K4CF70 (HPL). Homology-based modeling was done using Modeler 9.1.

\section{Interaction of AOS and HPL with their ligand molecules}

It was reported in the literature that Allene oxide synthase (AOS) catalyzes the first step of jasmonate biosynthesis in the chloroplast by interacting with 9 and 13- hydroxyperoxides ${ }^{37}$. The molecules of 9 and 13- hydroxyperoxides were selected as ligands for AOS and HPL. Protein-ligand docking was performed by using AutoDock Vina and protein-ligand interaction was visualized from LIGPLOT.

\section{Jasmonate signaling and regulation}

Jasmonic acid (JA) is generated in the peroxisome and transferred into cytoplasm. In cytoplasm, the active signal in defense signaling appears to be the amide-linked isoleucine conjugate JA-lle rather than JA itself. This JA-lle promotes the interaction of Coronatine Insensitive Protein 1 (COI1) and Jasmonate ZIM domain (JAZ) protein. Afterwards, 26S proteasome perform the ubiquitination of JAZ proteins and expression of downstream genes are activated by specific transcription factors.

\section{Interaction of COI1 with JA-lle}


Coronatine Insensitive Protein 1 (COI1) is a nucleus receptor that binds with the JA-lle (Jasmonate Isoleucine) to degrade JAZ protein. The 2D structure of JA-lle was obtained from PubChem while the 3D structure of COI1 was downloaded from RCSB PDB (PDB ID: 30GM). 30GM is the Structure of COI1-ASK1 in complex with coronatine and the JAZ1 degron. Chain B of the complex is COI1 and it was cut by using Chimera 1.8. The ligand JA-lle was docked with COI1 by Auto Dock Vina.

\section{Interaction of COI1 receptor with JAZ protein}

The 3D structure of the JAZ binding domain was downloaded from RCSB PDB (PDB ID: 4RS9) which is a structure of MYC3 N-terminal JAZ-binding domain complex with Jas motif of JAZ9. The chain B, JAZ degron, was cut and retrieved by Chimera 1.8.

The docked COI1-JA-lle complex was docked with JAZ by submitting to the Patch Dock server and complexes were refined through FireDock. The best-docked complex was downloaded and 2D interactions were visualized through DIMPLOT while for 3D complex visualization BIOVA DISCOVERY STUDIO ${ }^{\circ}$

\section{Protein-Protein interactions}

Protein-Protein interaction networks ${ }^{38}$ were used to understand biological processes in organisms. Protein-Protein interaction was explored, from protein-protein interaction database STRING, to find out the interactions of the target protein to other proteins which might be selected for alternate target site in future.

\section{Protein sequence and structure alignment}

Hydroperoxide lyase (HPL) and Allene oxide synthase (AOS) are involved in a same pathway for almost same functions that's why they are thought to be closely related. The pairwise sequence alignment was done by the EMBL_EBI Pairwise sequence alignment tool. Three-dimensional structure superposition was by Matchmaker of Chimera 1.8 .

\section{Declarations}

\section{Conflict of interest}

The authors declared no conflict of interest

\section{References}

1. Wu, J. \& Baldwin, I. T. New insights into plant responses to the attack from insect herbivores. Annual review of genetics. 44, 1-24 (2010).

2. Rani, P. U. \& Jyothsna, Y. Biochemical and enzymatic changes in rice plants as a mechanism of defense. Acta Physiol. Plant. 32, 695-701 (2010).

3. Turlings, T. C., Tumlinson, J. H. \& Lewis, W. J. Exploitation of herbivore-induced plant odors by hostseeking parasitic wasps. Science. 250, 1251-1253 (1990). 
4. Chen, C. Y. \& Mao, Y. B. Research advances in plant-insect molecular interaction. F1000Research $9(2020)$.

5. Futuyma, D. J. \& Agrawal, A. A. Macroevolution and the biological diversity of plants and herbivores. Proceedings of the National Academy of Sciences 106, 18054-18061(2009).

6. Agrawal, A. A. Macroevolution of plant defense strategies. Trends in ecology \& evolution. 22, 103109 (2007).

7. Koricheva, J. Meta-analysis of sources of variation in fitness costs of plant antiherbivore defenses. Ecology. 83, 176-190 (2002).

8. Redman, A. M., Cipollini, D. F. \& Schultz, J. C. Fitness costs of jasmonic acid-induced defense in tomato, Lycopersicon esculentum. Oecologia. 126, 380-385 (2001).

9. Karban, R. \& Baldwin, I. T. Induced responses to herbivory(University of Chicago Press, 1997).

10. Holopainen, J. K. \& Blande, J. D. Molecular plant volatile communication. Sensing in nature,1731(2012).

11. Markovic, D. et al. Airborne signals synchronize the defenses of neighboring plants in response to touch. Journal of experimental botany. 70, 691-700 (2019).

12. Salerno, G. et al. Mating status of an herbivorous stink bug female affects the emission of oviposition-induced plant volatiles exploited by an egg parasitoid. Frontiers in physiology. 10, 398 (2019).

13. Ray, S. et al. Lessons from the far end: caterpillar frass-induced defenses in maize, rice, cabbage, and tomato. Journal of chemical ecology. 42, 1130-1141 (2016).

14. Helms, A. M. et al. Identification of an insect-produced olfactory cue that primes plant defenses. Nature communications. 8, 1-9 (2017).

15. Pinto, C. F. et al. Chemical responses of Nicotiana tabacum (Solanaceae) induced by vibrational signals of a generalist herbivore. Journal of chemical ecology. 45, 708-714 (2019).

16. Erb, M. \& Reymond, P. Molecular interactions between plants and insect herbivores. Annual Review of Plant Biology. 70, 527-557 (2019).

17. Acevedo, F. E., Rivera-Vega, L. J., Chung, S. H., Ray, S. \& Felton, G. W. Cues from chewing insects-the intersection of DAMPs, HAMPs, MAMPs and effectors. Current Opinion in Plant Biology. 26, 80-86 (2015).

18. Doss, R. P. et al. Bruchins: insect-derived plant regulators that stimulate neoplasm formation. Proceedings of the National Academy of Sciences 97, 6218-6223(2000).

19. Alborn, H. et al. An elicitor of plant volatiles from beet armyworm oral secretion. Science. 276, 945949 (1997).

20. Schmelz, E. A. et al. Fragments of ATP synthase mediate plant perception of insect attack. Proceedings of the National Academy of Sciences 103, 8894-8899(2006).

21. Steinbrenner, A. D. et al. A receptor for herbivore-associated molecular patterns mediates plant immunity. Biorxiv,679803(2019). 
22. Fürstenberg-Hägg, J., Zagrobelny, M. \& Bak, S. Plant defense against insect herbivores. International journal of molecular sciences. 14, 10242-10297 (2013).

23. Pearce, G., Strydom, D., Johnson, S. \& Ryan, C. A. A polypeptide from tomato leaves induces woundinducible proteinase inhibitor proteins. Science. 253, 895-897 (1991).

24. Orozco-Cardenas, M., McGurl, B. \& Ryan, C. A. Expression of an antisense prosystemin gene in tomato plants reduces resistance toward Manduca sexta larvae. Proceedings of the National Academy of Sciences 90, 8273-8276(1993).

25. Wang, L. et al. The systemin receptor SYR1 enhances resistance of tomato against herbivorous insects. Nature plants. 4, 152-156 (2018).

26. Shinya, T. et al. Integration of danger peptide signals with herbivore-associated molecular pattern signaling amplifies anti-herbivore defense responses in rice. Plant J. 94, 626-637 (2018).

27. Huffaker, A., Pearce, G. \& Ryan, C. A. An endogenous peptide signal in Arabidopsis activates components of the innate immune response. Proceedings of the National Academy of Sciences 103, 10098-10103(2006).

28. Yamaguchi, Y., Huffaker, A., Bryan, A. C., Tax, F. E. \& Ryan, C. A. PEPR2 is a second receptor for the Pep1 and Pep2 peptides and contributes to defense responses in Arabidopsis. The Plant Cell. 22, 508-522 (2010).

29. Yamaguchi, Y., Pearce, G. \& Ryan, C. A. The cell surface leucine-rich repeat receptor for AtPep1, an endogenous peptide elicitor in Arabidopsis, is functional in transgenic tobacco cells. Proceedings of the National Academy of Sciences 103, 10104-10109(2006).

30. Farmer, E. E., Alméras, E. \& Krishnamurthy, V. Jasmonates and related oxylipins in plant responses to pathogenesis and herbivory. Current opinion in plant biology. 6, 372-378 (2003).

31. Howe, G. A. \& Jander, G. Plant immunity to insect herbivores. Annu. Rev. Plant Biol. 59, 41-66 (2008).

32. Sharma, H. C. Biotechnological approaches for pest management and ecological sustainability(CRC Press, 2008).

33. Agrawal, A. A. Current trends in the evolutionary ecology of plant defence. Funct. Ecol. 25, 420-432 (2011).

34. Xu, D. \& Zhang, Y. Improving the physical realism and structural accuracy of protein models by a twostep atomic-level energy minimization. Biophysical journal. 101, 2525-2534 (2011).

35. Schneidman-Duhovny, D., Inbar, Y., Nussinov, R. \& Wolfson, H. J. PatchDock and SymmDock: servers for rigid and symmetric docking. Nucleic acids research. 33, W363-W367 (2005).

36. Design, L. Pharmacophore and ligand-based design with Biovia Discovery Studio®. (2014).

37. Stumpe, M. \& Feussner, I. Formation of oxylipins by CYP74 enzymes. Phytochem. Rev. 5, 347-357 (2006).

38. Silletta, M. G. et al. CLINICAL PERSPECTIVE. Circulation. 116, 2944-2951 (2007).

39. Zhang, J. et al. Identification and characterization of circRNAs responsive to methyl jasmonate in Arabidopsis thaliana. International journal of molecular sciences. 21, 792 (2020). 
40. Acevedo, F. E. et al. Intraspecific differences in plant defense induction by fall armyworm strains. New phytologist. 218, 310-321 (2018).

41. Chen, C. Y. et al. An effector from cotton bollworm oral secretion impairs host plant defense signaling. Proceedings of the National Academy of Sciences 116, 14331-14338(2019).

42. Huang, H. J. et al. Salivary DN ase II from Laodelphax striatellus acts as an effector that suppresses plant defence. New Phytol. 224, 860-874 (2019).

43. Wu, J., Hettenhausen, C., Meldau, S. \& Baldwin, I. T. Herbivory rapidly activates MAPK signaling in attacked and unattacked leaf regions but not between leaves of Nicotiana attenuata. The Plant Cell. 19, 1096-1122 (2007).

44. Okada, K., Abe, H. \& Arimura, G. -i. Jasmonates induce both defense responses and communication in monocotyledonous and dicotyledonous plants. Plant and Cell Physiology. 56, 16-27 (2015).

45. Zhang, Y. I-TASSER server for protein 3D structure prediction. BMC bioinformatics. 9, 1-8 (2008).

46. Roy, A., Kucukural, A. \& Zhang, Y. I-TASSER: a unified platform for automated protein structure and function prediction. Nature protocols. 5, 725-738 (2010).

47. Yang, J. \& Zhang, Y. I-TASSER server: new development for protein structure and function predictions. Nucleic acids research. 43, W174-W181 (2015).

48. Wiley, J. Sons Vol. 1 (Inc New York, NY, 2001).

49. Schmelz, E. A., Alborn, H. T. \& Tumlinson, J. H. Synergistic interactions between volicitin, jasmonic acid and ethylene mediate insect-induced volatile emission in Zea mays. Physiol. Plant. 117, 403412 (2003).

50. Wasternack, C., Strnad, M. \& Jasmonates News on occurrence, biosynthesis, metabolism and action of an ancient group of signaling compounds. International journal of molecular sciences. 19, 2539 (2018).

51. Block, A., Schmelz, E., Jones, J. B. \& Klee, H. J. Coronatine and salicylic acid: the battle between Arabidopsis and Pseudomonas for phytohormone control. Mol. Plant Pathol. 6, 79-83 (2005).

52. Baldwin, I. T., Halitschke, R., Paschold, A., Von Dahl, C. C. \& Preston, C. A. Volatile signaling in plantplant interactions:" talking trees" in the genomics era. science 311, 812-815(2006).

53. Matsui, K. Green leaf volatiles: hydroperoxide lyase pathway of oxylipin metabolism. Current opinion in plant biology. 9, 274-280 (2006).

54. Truman, W., Bennett, M. H., Kubigsteltig, I., Turnbull, C. \& Grant, M. Arabidopsis systemic immunity uses conserved defense signaling pathways and is mediated by jasmonates. Proceedings of the national academy of sciences 104, 1075-1080(2007).

55. Yan, J. et al. The Arabidopsis CORONATINE INSENSITIVE1 protein is a jasmonate receptor. The Plant Cell. 21, 2220-2236 (2009).

56. Sheard, L. B. et al. Jasmonate perception by inositol-phosphate-potentiated COI1-JAZ co-receptor. Nature. 468, 400-405 (2010).

57. Anslyn, E. V. \& Dougherty, D. A. Modern physical organic chemistry(University science books, 2006). 
58. Kumar, S. \& Nussinov, R. Close-range electrostatic interactions in proteins. ChemBioChem. 3, 604617 (2002).

59. Thines, B. et al. JAZ repressor proteins are targets of the SCF COI1 complex during jasmonate signalling. Nature. 448, 661-665 (2007).

60. Krumm, T., Bandemer, K. \& Boland, W. Induction of volatile biosynthesis in the Lima bean (Phaseolus lunatus) by leucine-and isoleucine conjugates of 1-oxo-and 1-hydroxyindan-4-carboxylic acid: evidence for amino acid conjugates of jasmonic acid as intermediates in the octadecanoid signalling pathway. FEBS letters. 377, 523-529 (1995).

61. Farmer, E. E. \& Ryan, C. A. Octadecanoid precursors of jasmonic acid activate the synthesis of wound-inducible proteinase inhibitors. The Plant Cell. 4, 129-134 (1992).

62. Lee, D. S., Nioche, P., Hamberg, M. \& Raman, C. Structural insights into the evolutionary paths of oxylipin biosynthetic enzymes. Nature. 455, 363-368 (2008).

63. Cho, K. B., Lai, W., Hamberg, M., Raman, C. \& Shaik, S. The reaction mechanism of allene oxide synthase: interplay of theoretical QM/MM calculations and experimental investigations. Archives of biochemistry and biophysics. 507, 14-25 (2011).

64. Paré, P. W. \& Tumlinson, J. H. Plant volatiles as a defense against insect herbivores. Plant physiology. 121, 325-332 (1999).

65. Schaller, F. Enzymes of the biosynthesis of octadecanoid-derived signalling molecules. Journal of experimental botany. 52, 11-23 (2001).

66. Strassner, J. et al. Characterization and cDNA-microarray expression analysis of 12oxophytodienoate reductases reveals differential roles for octadecanoid biosynthesis in the local versus the systemic wound response. Plant J. 32, 585-601 (2002).

67. Stenzel, I. et al. Jasmonate biosynthesis and the allene oxide cyclase family of Arabidopsis thaliana. Plant molecular biology. 51, 895-911 (2003).

68. Viswanath, K. K. et al. Plant lipoxygenases and their role in plant physiology. Journal of Plant Biology. 63, 83-95 (2020).

69. Alka, K., Windle, H. J., Cornally, D., Ryan, B. J. \& Henehan, G. T. A short chain NAD(H)-dependent alcohol dehydrogenase (HpSCADH) from Helicobacter pylori: a role in growth under neutral and acidic conditions. The international journal of biochemistry \& cell biology. 45, 1347-1355 https://doi.org/10.1016/j.biocel.2013.04.006 (2013).

70. Salas, J. J., Sánchez, C., García-González, D. L. \& Aparicio, R. Impact of the suppression of lipoxygenase and hydroperoxide lyase on the quality of the green odor in green leaves. Journal of agricultural and food chemistry. 53, 1648-1655 (2005).

71. Matsui, K. Green leaf volatiles: hydroperoxide lyase pathway of oxylipin metabolism. Curr Opin Plant Biol. 9, 274-280 https://doi.org/10.1016/j.pbi.2006.03.002 (2006).

72. Thompson, C. E., Salzano, F. M., de Souza, O. N. \& Freitas, L. B. Sequence and structural aspects of the functional diversification of plant alcohol dehydrogenases. Gene. 396, 108-115 https://doi.org/10.1016/j.gene.2007.02.016 (2007). 
73. Engelberth, J., Alborn, H. T., Schmelz, E. A. \& Tumlinson, J. H. Airborne signals prime plants against insect herbivore attack. Proceedings of the National Academy of Sciences 101, 1781-1785(2004).

74. Conrath, U. Priming of induced plant defense responses. Advances in botanical research. 51, 361395 (2009).

75. Tyagi, C., Singh, A. \& Singh, I. K. Mechanistic insights into mode of action of rice allene oxide synthase on hydroxyperoxides: An intermediate step in herbivory-induced jasmonate pathway. Computational biology and chemistry. 64, 227-236 (2016).

76. Liu, X. et al. Activation of the jasmonic acid pathway by depletion of the hydroperoxide lyase OsHPL3 reveals crosstalk between the HPL and AOS branches of the oxylipin pathway in rice. PLOS One. 7, e50089 (2012).

\section{Tables}

Due to technical limitation the tables are available as a download in the Supplementary Files.

\section{Figures}




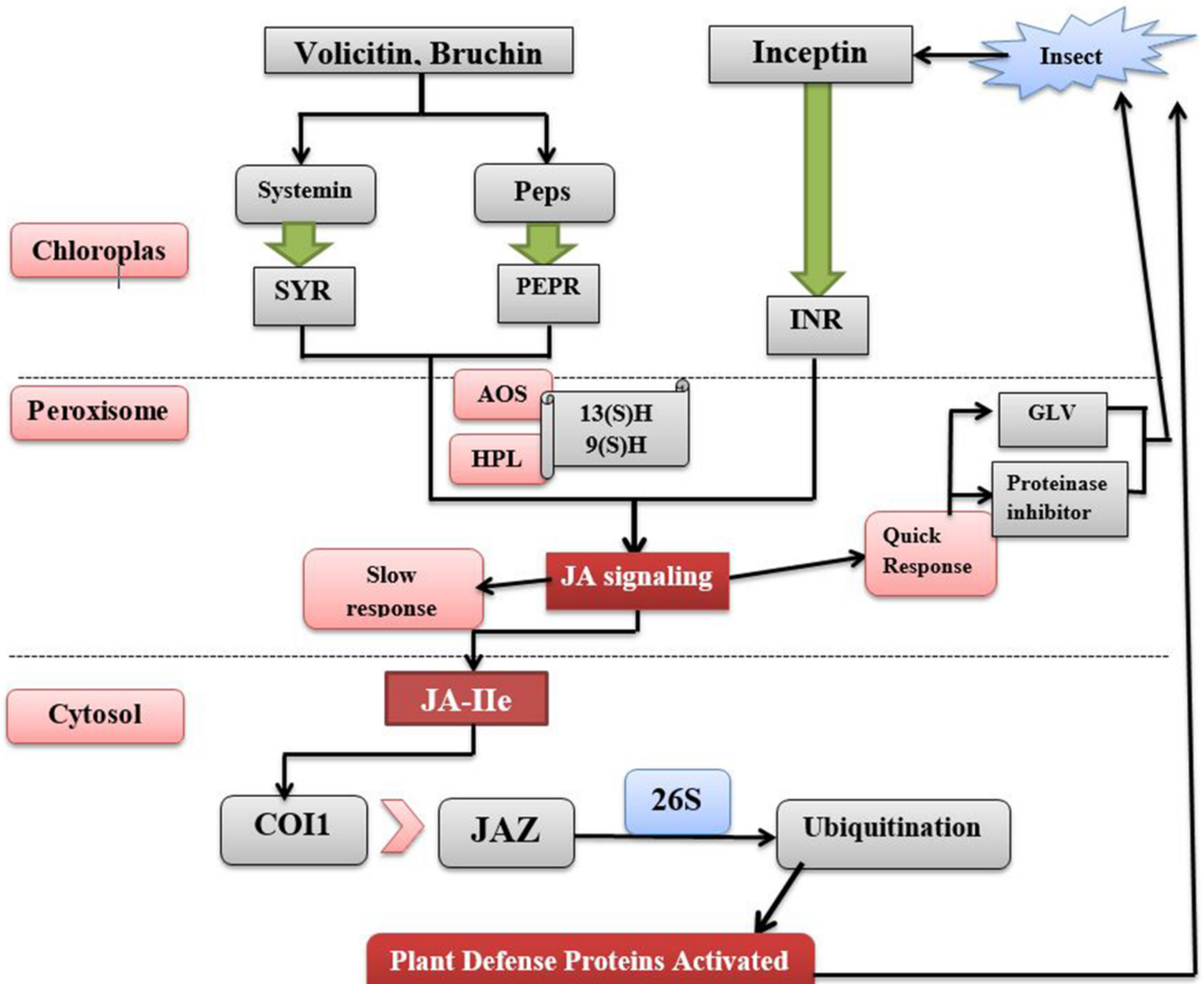

Figure 1

Herbivory induced plant defense pathway 


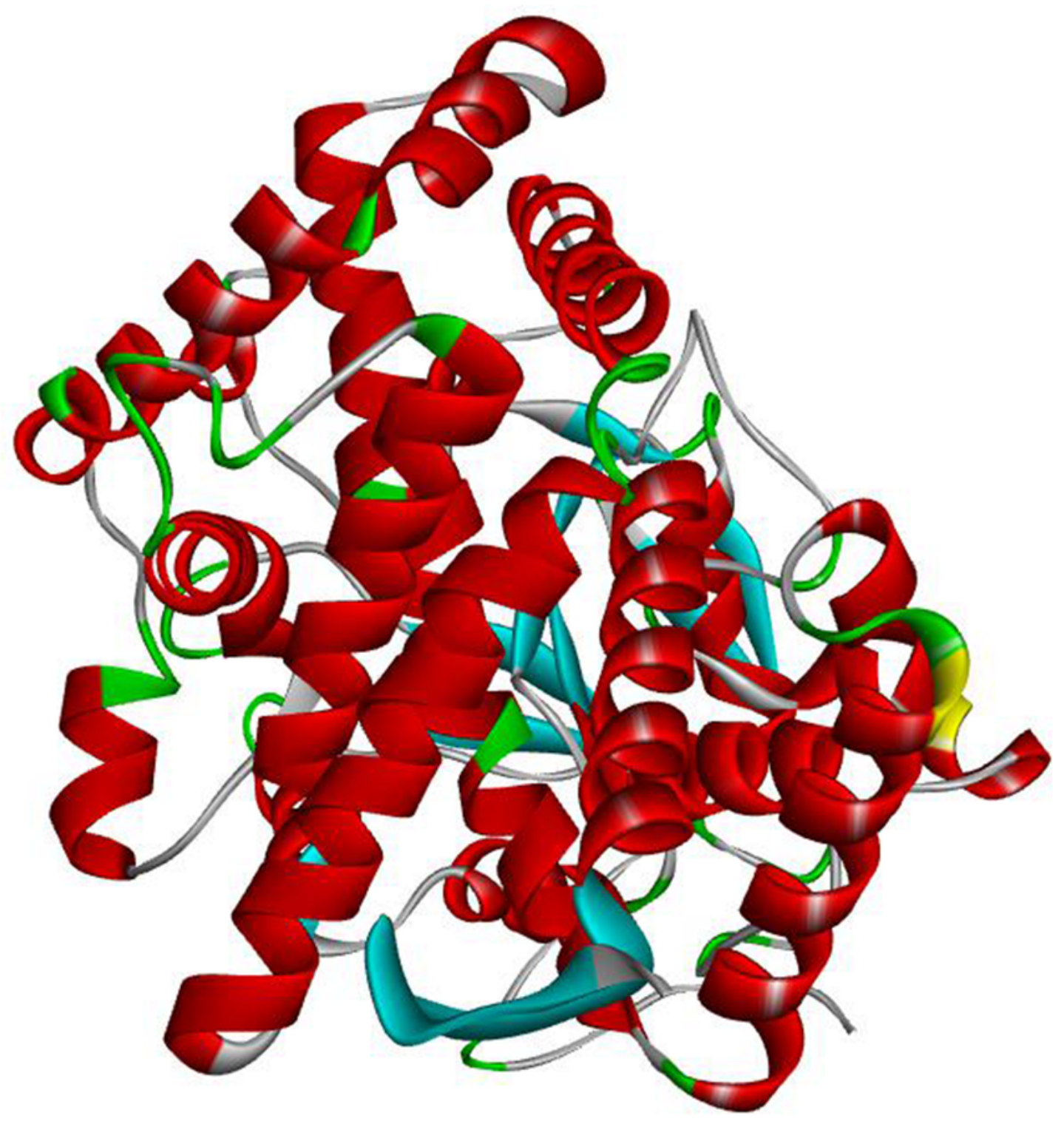

Figure 2

Predicted 3D structure of allene oxide synthase (AOS) of Solanum lycopersicum 


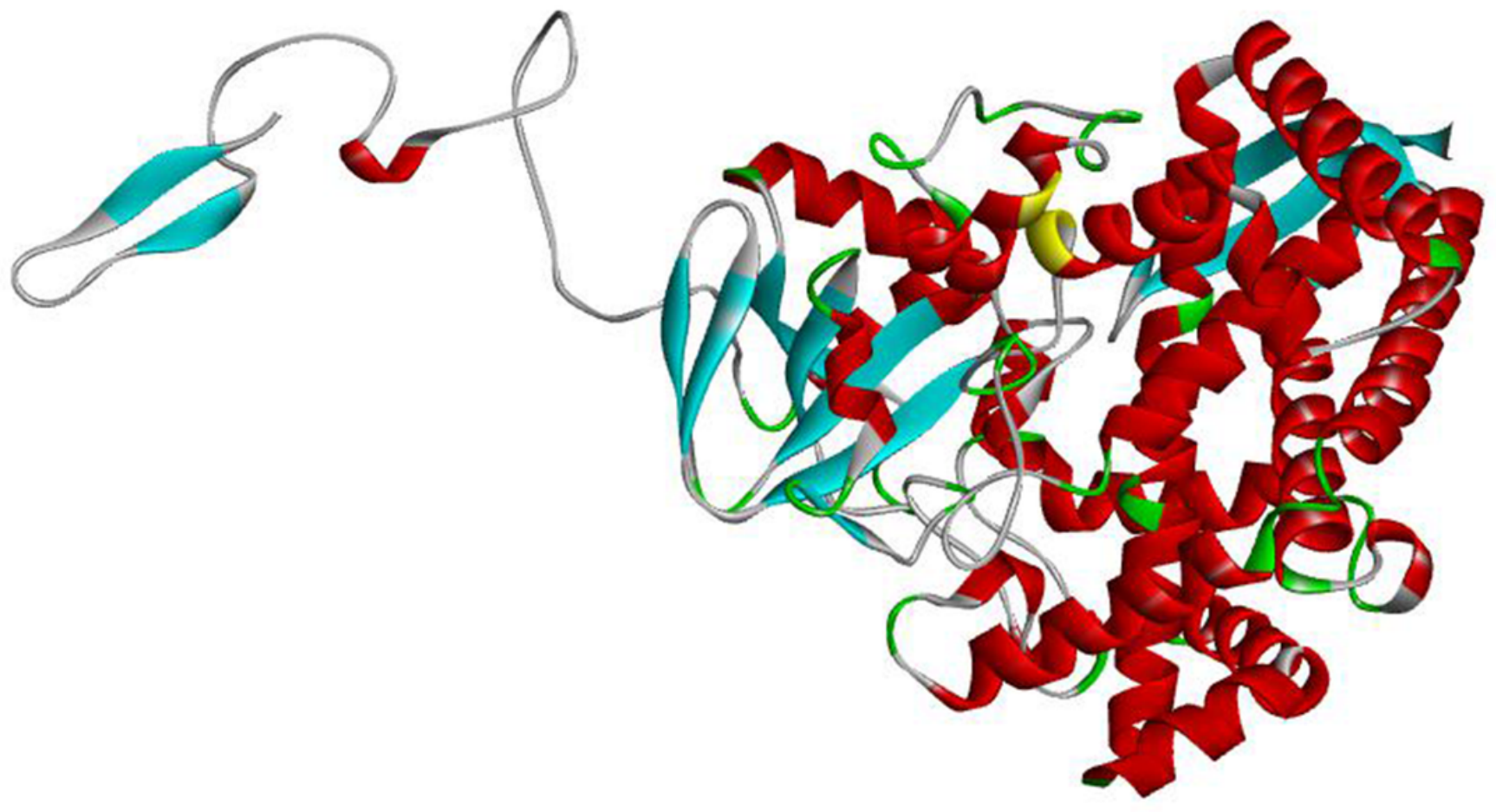

Figure 3

Predicted 3D structure of hydroxperoxide lyase (HPL) of Solanum lycopersicum 

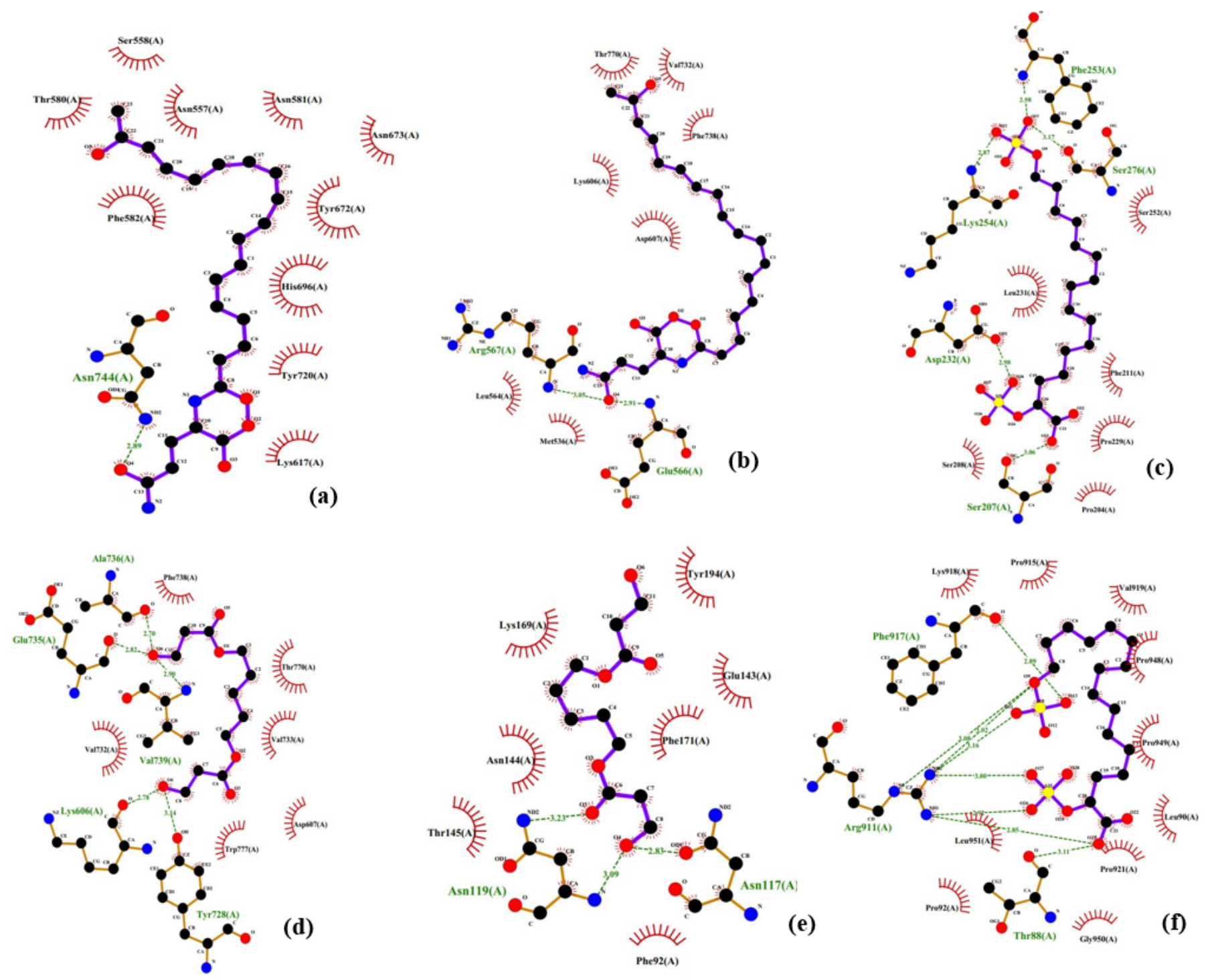

Figure 4

Protein-ligand 2D interaction map a. Systemin-voliticin b. PEP-voliticin c. Systemin- caeliferin d. PEPbruchin e.Systemin-bruchin f. PEP- caeliferin 


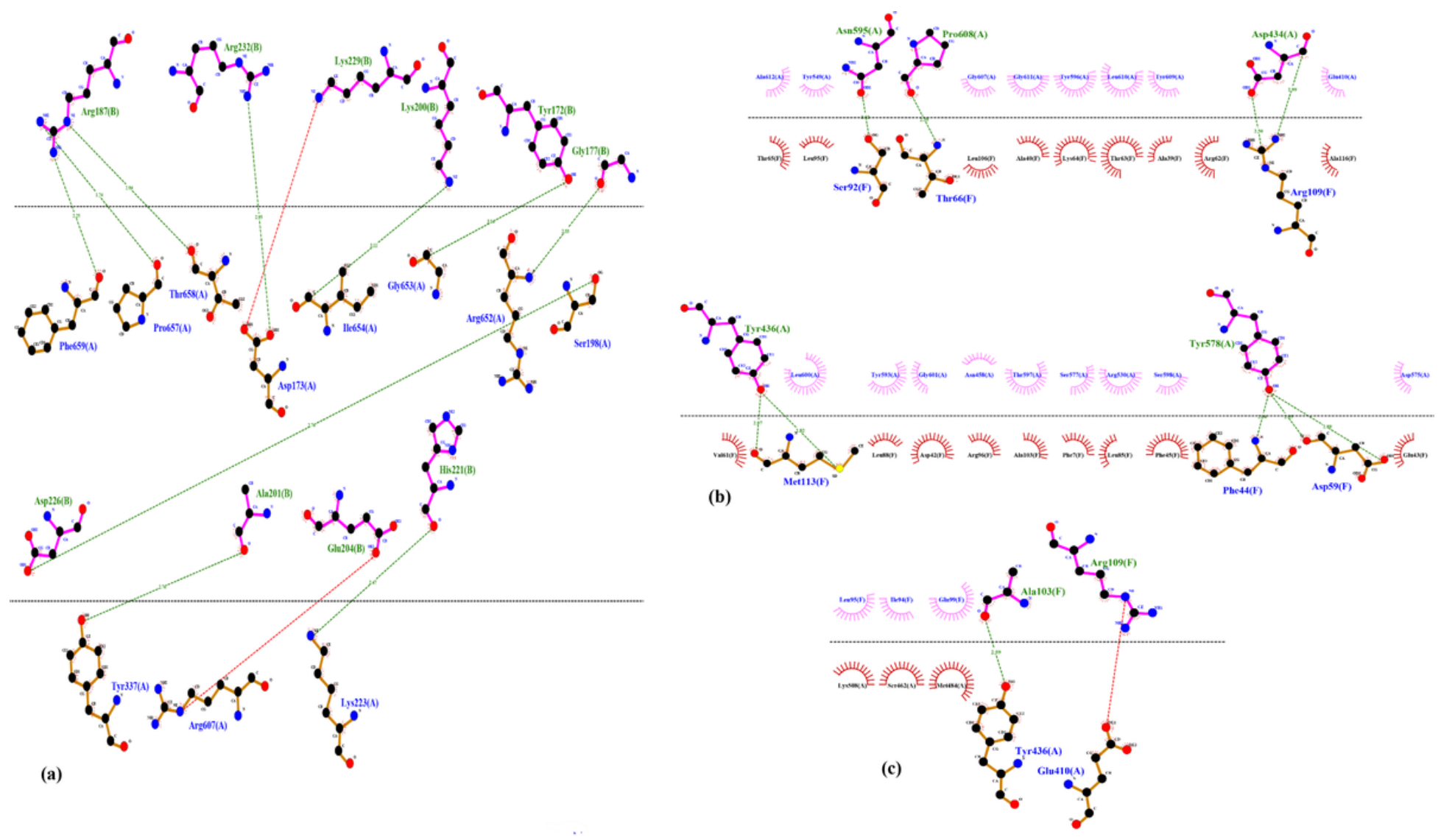

Figure 5

Protein-protein 2D interaction map a. Systemin-SYR b. PEP-PEPR c. Inceptin-LRR 

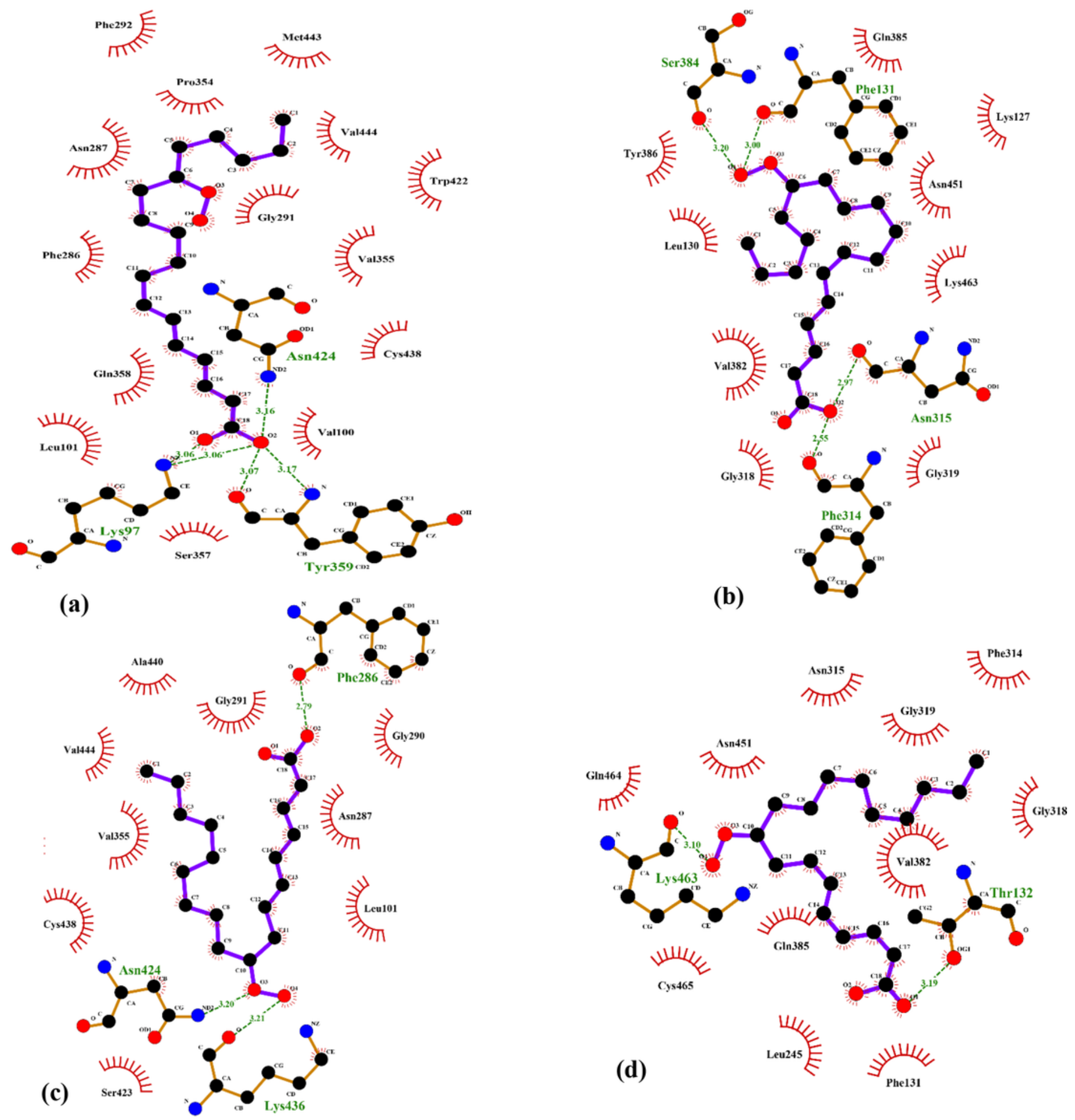

Figure 6

2D interaction map for Protein-ligand in jasmonate biosynthesis pathway a.13(S) Hydroperoxide-HPL complex b. 13(S) Hydroperoxide-AOS complex c. 9(S) Hydroperoxide-HPL complex d. 9(S) HydroperoxideAOS complex 

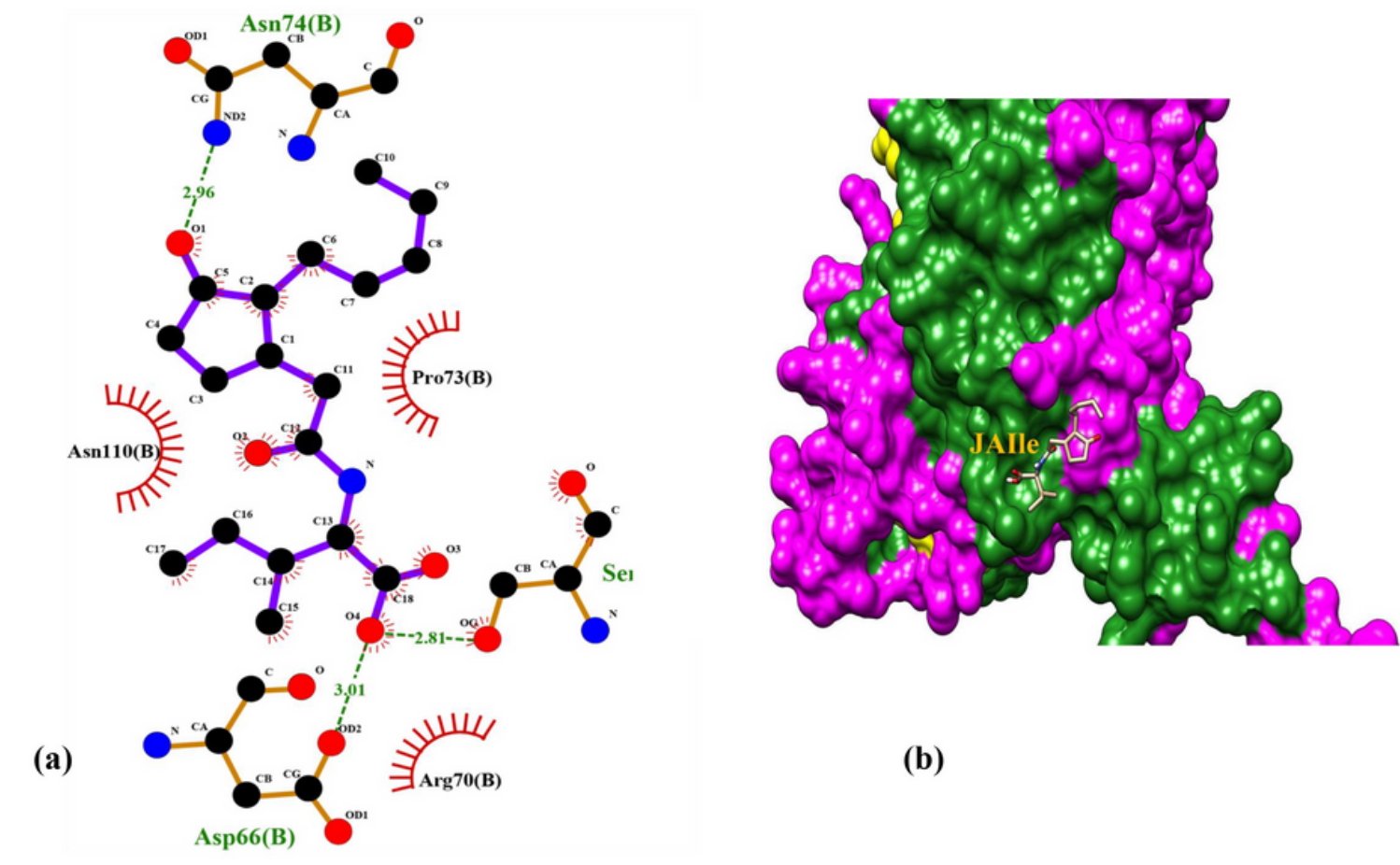

(b)

Figure 7

Interaction of COI1 with JA-lle in Jasmonic acid induce plant defense mechanism a. 2 D interaction plot b. 3D complex

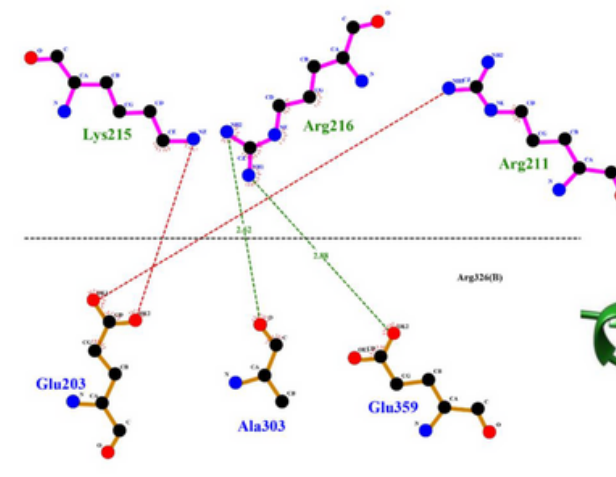

(a)
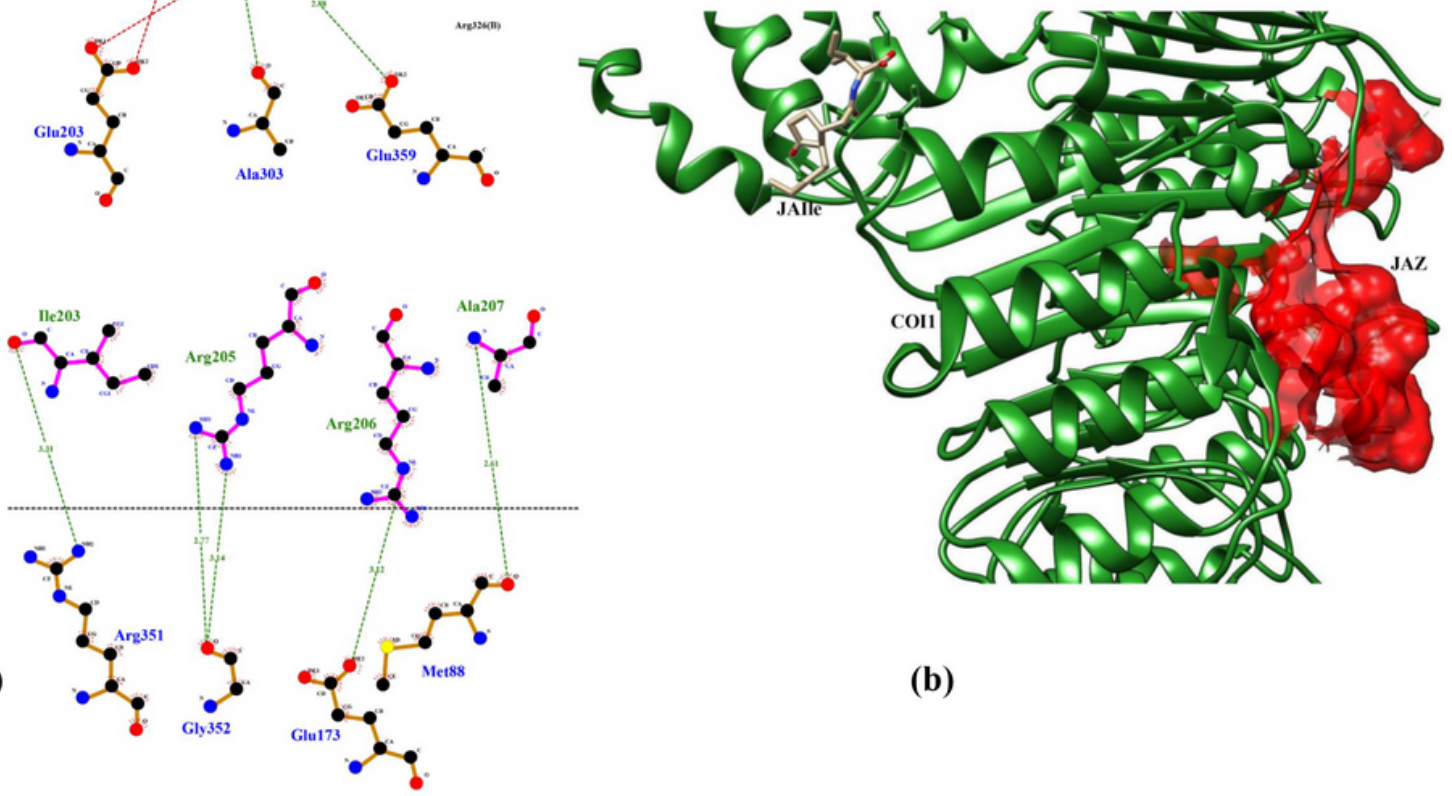

(b) 
Figure 8

Interaction of COI1- JA-lle complex with JAZ protein degron in Jasmonic acid induce plant defense mechanism a. $2 \mathrm{D}$ interaction plot b. 3D complex

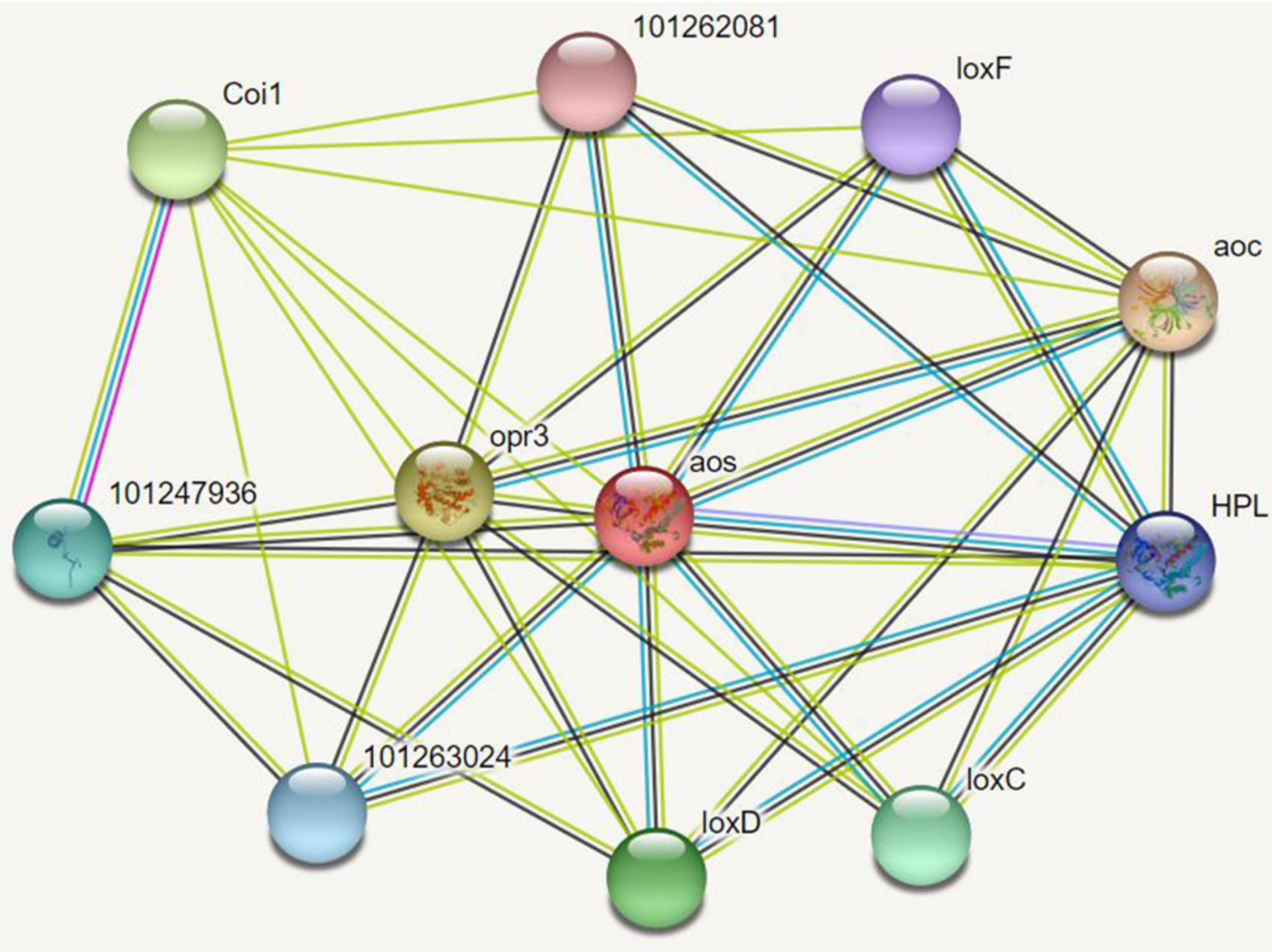

\section{Figure 9}

Protein interaction partners of allene oxide synthase (AOS) of Solanum lycopersicum 


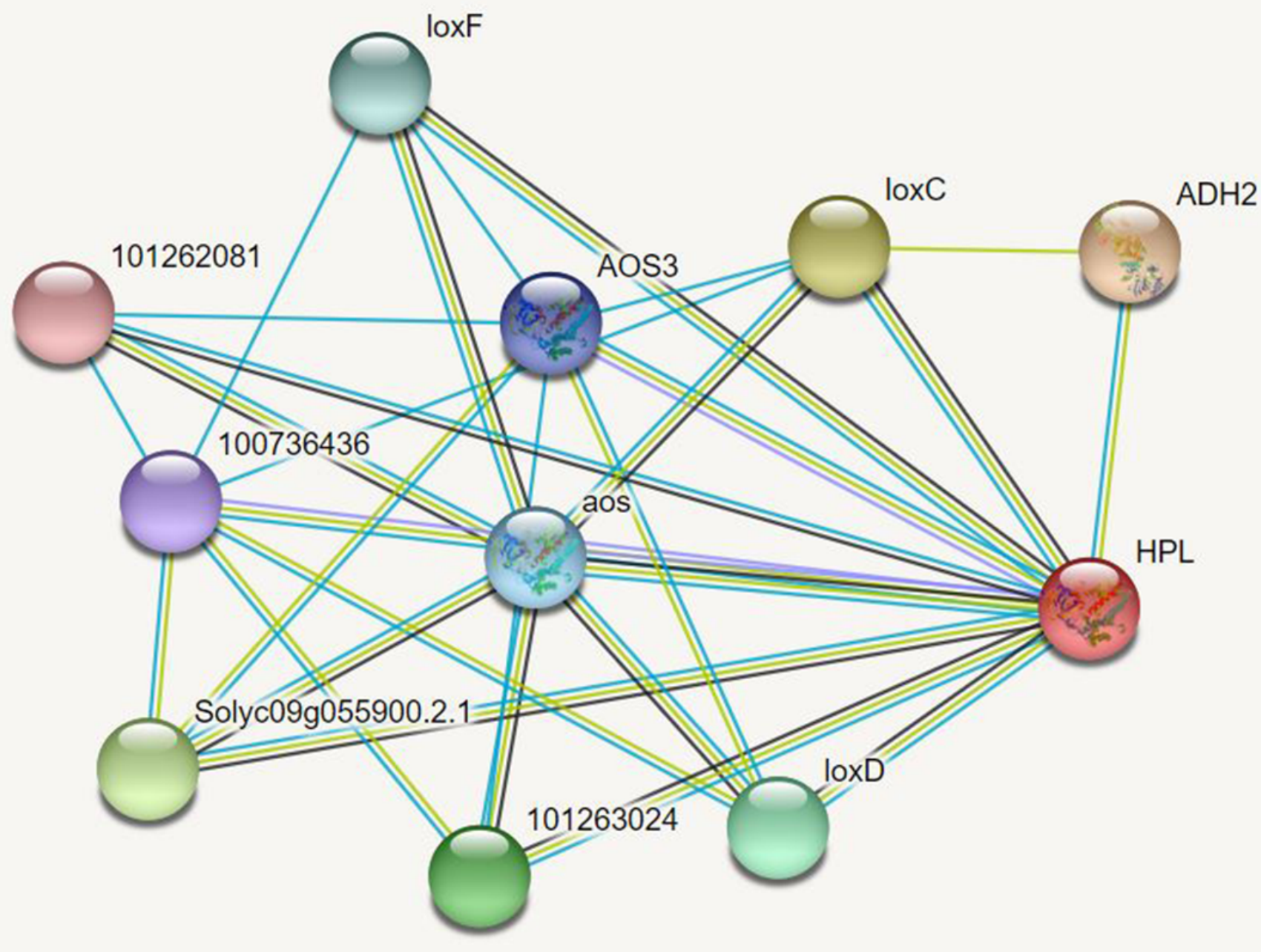

Figure 10

Protein interaction partners of hydroxyperoxide lyase $(\mathrm{HPL})$ of Solanum lycopersicum 


\begin{tabular}{|c|c|c|c|}
\hline AOS2_SOLLC & & 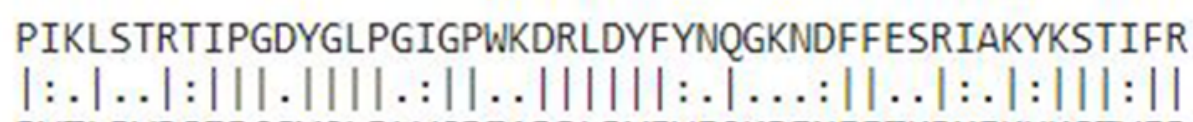 & 92 \\
\hline HPL_SOLLC & 11 & PVTLPVRSIPGSYGLPLVGPIADRLDYFWFQKPENFFTKRMEKHKSTVFR & 60 \\
\hline AOS2_SOLLC & 93 & 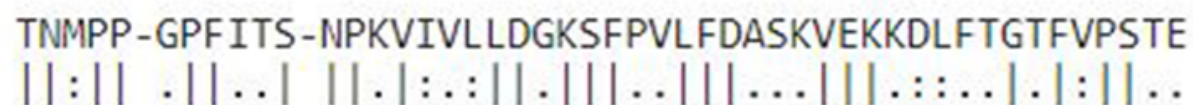 & 140 \\
\hline HPL_SOLLC & 61 & TNVPPCFPFFGSVNPNVVAVLDVKSFSHLFDMEIVEKANVLVGDFMPSVV & 110 \\
\hline AOS2_SOLLC & 141 & 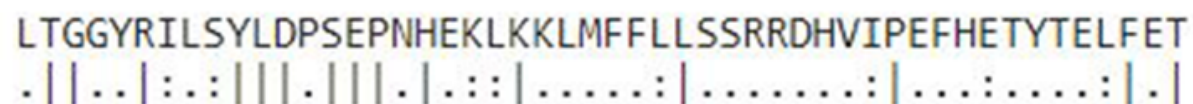 & 190 \\
\hline HPL_SOLLC & 111 & YTGDMRVCAYLDTSEPKHAQIKNFSQDILKRGSKTWVPTLLKELDTMFTT & 160 \\
\hline AOS2_SOLLC & 191 & LDKEMEEKGTVGFNSGSDQAAFNFLARSLFGVNP-VETKLGTDGPALIGK & 239 \\
\hline HPL_SOLLC & 161 & FEADLSKSNTASLLPALQKFLFNFFSLTILGADPSVSPEIANSGYIFLDS & 210 \\
\hline AOS2_SOLLC & 240 & 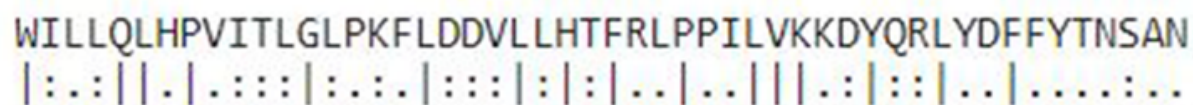 & 289 \\
\hline HPL_SOLLC & 211 & WLAIQLAPTVSIGVLQPLEEILVHSFAYPFFLVKGNYEKLVQFVKNEAKE & 260 \\
\hline AOS2_SOLLC & 290 & 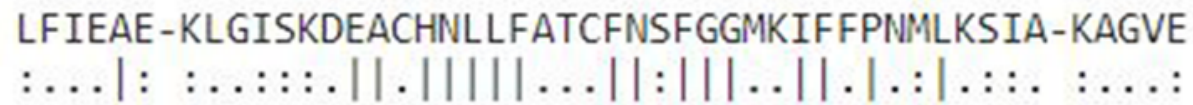 & 337 \\
\hline HPL_SOLLC & 261 & VLSRAQTEFQLTEQEAIHNLLFILGFNAFGGFSIFLPTLLGNLGDEKNAD & 310 \\
\hline AOS2_SOLLC & 338 & 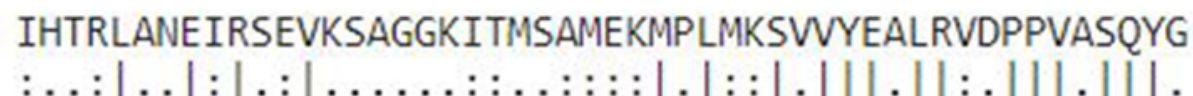 & 387 \\
\hline HPL_SOLLC & 311 & MQEKLRKEVRDKVGVNPENLSFESVKEMELVQSFVYETLRLSPPVPSQYA & 360 \\
\hline AOS2_SOLLC & 388 & 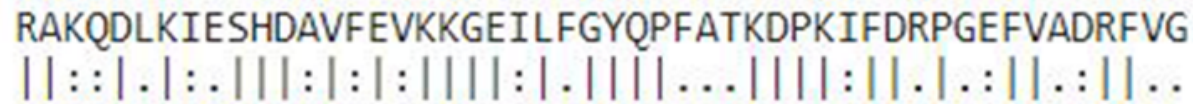 & 437 \\
\hline HPL_SOLLC & 361 & RARKDFKLSSHDSVYEIKKGELLCGYQPLVMKDPKVFDEPEKFVLERFTK & 410 \\
\hline AOS2_SOLLC & 438 & 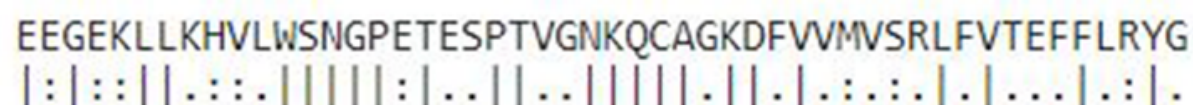 & 487 \\
\hline HPL_SOLLC & 411 & EKGKELLNYLFWSNGPQTGRPTESNKQCAAKDMVTLTASLIVAYIFQKYD & 460 \\
\hline AOS2_SOLLC & 488 & TLNVDVGTSALGSSITITSLKKA & \\
\hline HPL_SOLLC & 461 & SVSF-.....-.SSGSLTSVKKA & \\
\hline
\end{tabular}

\section{Figure 11}

Pairwise sequence alignment of allene oxide synthase (AOS) and hydroxyperoxide lyase (HPL) of Solanum lycopersicum 


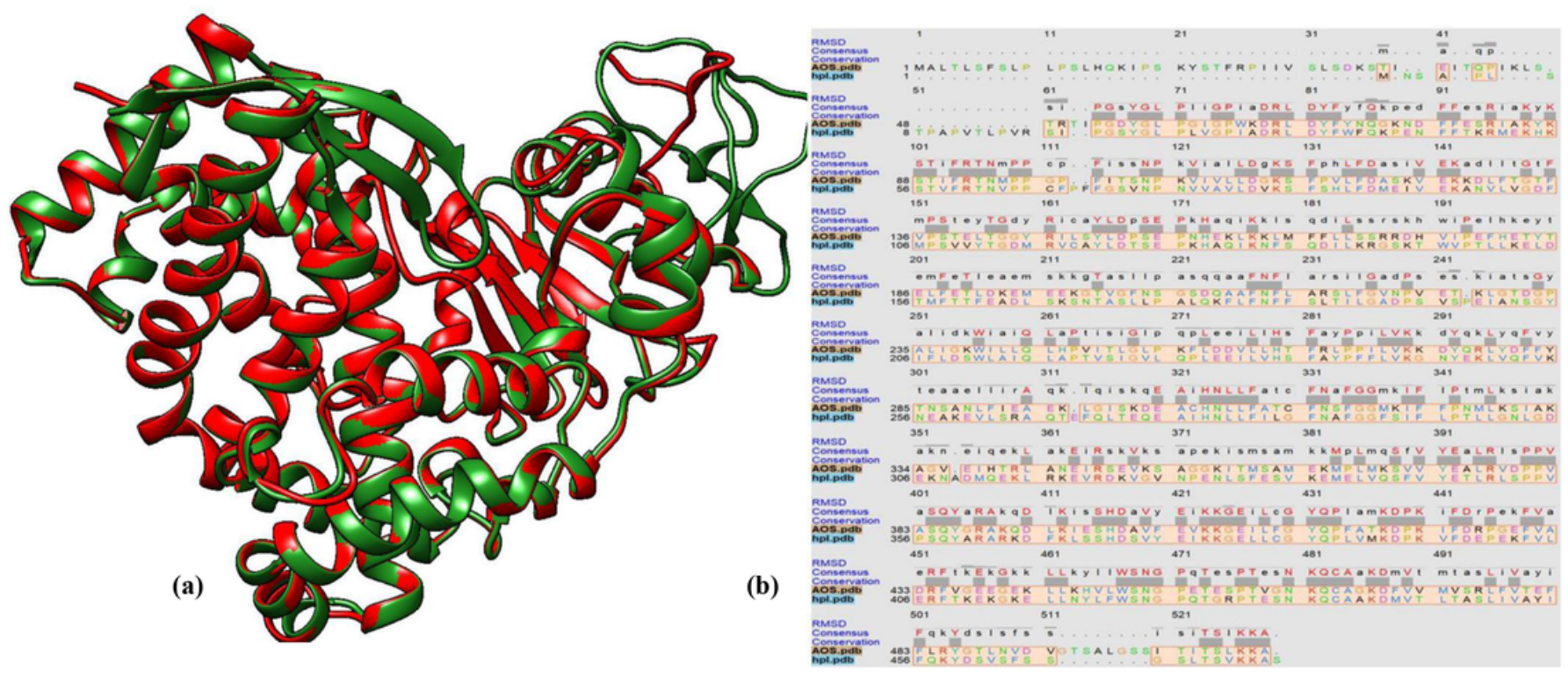

Figure 12

Three dimensional structure superposition of allene oxide synthase (AOS) and hydroxyperoxide lyase (HPL) of Solanum lycopersicum a. 3D superposed complex b. pairwise sequence alignment during structure superposition.

\section{Supplementary Files}

This is a list of supplementary files associated with this preprint. Click to download.

- Tables.pdf

- Graphicalabstract.png 